\title{
Hypoplastic left heart syndrome - a review of supportive percutaneous treatment
}

\author{
Tomasz Moszura ${ }^{1,2}$, Sebastian Góreczny ${ }^{1}$, Paweł Dryżek ${ }^{1}$ \\ 1Department of Cardiology, Polish Mothers Memorial Hospital, Research Institute, Lodz, Poland \\ 2Department of Paediatric Cardiology and Nephrology, Poznan University of Medical Sciences, Poland
}

Postep Kardiol Inter 2014; 10, 3 (37): 201-208

DOI: $10.5114 /$ pwki.2014.45148

\begin{abstract}
A bstract
Due to the complex anatomical and haemodynamic consequences of hypoplastic left heart syndrome (HLHS), patients with the condition require multistage surgical and supportive interventional treatment. Percutaneous interventions may be required between each stage of surgical palliation, sometimes simultaneously with surgery as hybrid interventions, or after completion of multistage treatment. Recent advances in the field of interventional cardiology, including new devices and techniques, have significantly contributed to improving results of multistage HLHS palliation. Knowledge of the potential interventional options as well as the limitation of percutaneous interventions will enable the creation of safe and effective treatment protocols in this highly challenging group of patients. In this comprehensive review we discuss the types, goals, and potential complications of transcatheter interventions in patients with HLHS.
\end{abstract}

Key words: hypoplastic left heart syndrome, percutaneous treatment.

\section{Introduction}

Due to the complex anatomical and haemodynamic consequences of hypoplastic left heart syndrome (HLHS), patients with the condition require multistage surgical and supportive interventional treatment [1]. Percutaneous interventions may be required between each stage of surgical palliation, sometimes simultaneously with surgery as hybrid interventions, or after completion of multistage treatment (Figures $1 \mathrm{~A}-\mathrm{C}$ ). In this comprehensive review we discuss the types, goals, and potential complications of transcatheter interventions in patients with HLHS.

\section{Aortic arch stenosis}

Aortic arch stenosis is one of the most challenging complications after the Norwood operation. In this group of patients a gradient of more than $10 \mathrm{~mm} \mathrm{Hg}$ is considered an indication for the treatment [1-4]. This relatively aggressive approach is due to the unique physiology of a single ventricle, where even a small increase in afterload may lead to the onset or progression of tricuspid valve regurgitation.

Balloon dilation, preferably with high-pressure catheters, is the treatment of choice. The diameter of the balloon should not significantly exceed the diameter of thoracic aorta below the obstruction. The lesion may be approached either through venous or arterial access; a venous approach reduces the risk of vascular complications (haematoma, thrombosis) and allows for a larger vascular sheath to be introduced. It may be difficult to precisely position the balloon at the site of the obstruction, and, as the catheter has to be advanced through two valves (tricuspid and neo-aortic), catheter induced regurgitation may lead to haemodynamic instability. In addition, manipulation with a balloon catheter in the aortic arch, especially a slowly deflating high-pressure one, may cause compression of the native ascending aorta with compromise of the coronary circulation. When arterial access is utilised, manipulation of the balloon catheter is more straightforward and less risky; however, this approach carries a much higher risk of vascular complications.

\section{Restrictive interatrial communication}

In patients with HLHS, unrestrictive interatrial communication is important for the development of normal pulmonary vasculature, which in turn contributes to low pulmonary vascular resistance and the completion of Fontan pathway palliation $[5,6]$. If restriction of the interatrial communication develops early in foetal life, the

\section{Corresponding author:}

Sebastian Góreczny MD, PhD, Department of Cardiology, Polish Mothers Memorial Hospital, Research Institute, 281/289 Rzgowska St, 93-338 Lodz, Poland, phone: +48 4227121 84, fax: +48 4227114 78, e-mail: sebstiangoreczny@yahoo.pl

Received: 24.07.2014, accepted: 1.09.2014. 
A
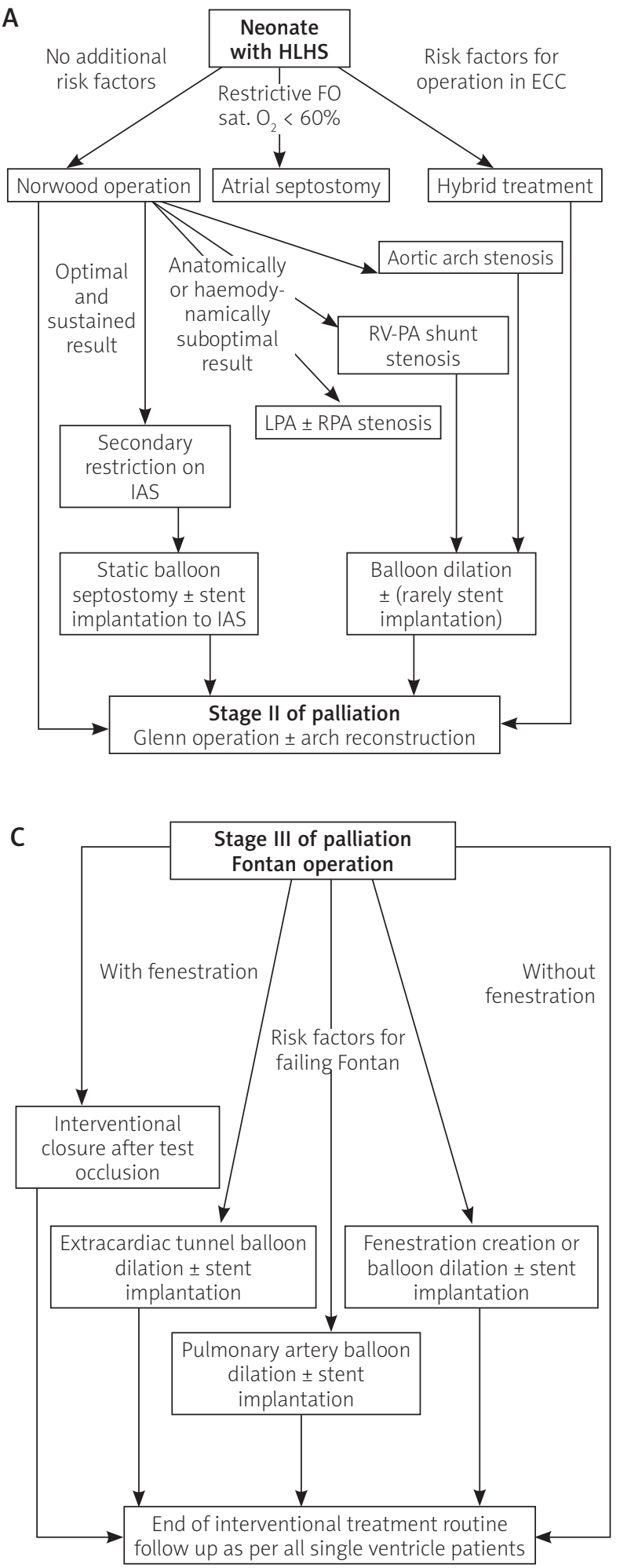

pulmonary vasculature may respond with adaptive and potentially irreversible changes, leading to significantly poorer survival rates [7].

In this group of patients the left atrium is usually small and the communication is localised relatively high in the atrial septum, which makes the classical balloon atrial septostomy more challenging. Alternatively, static

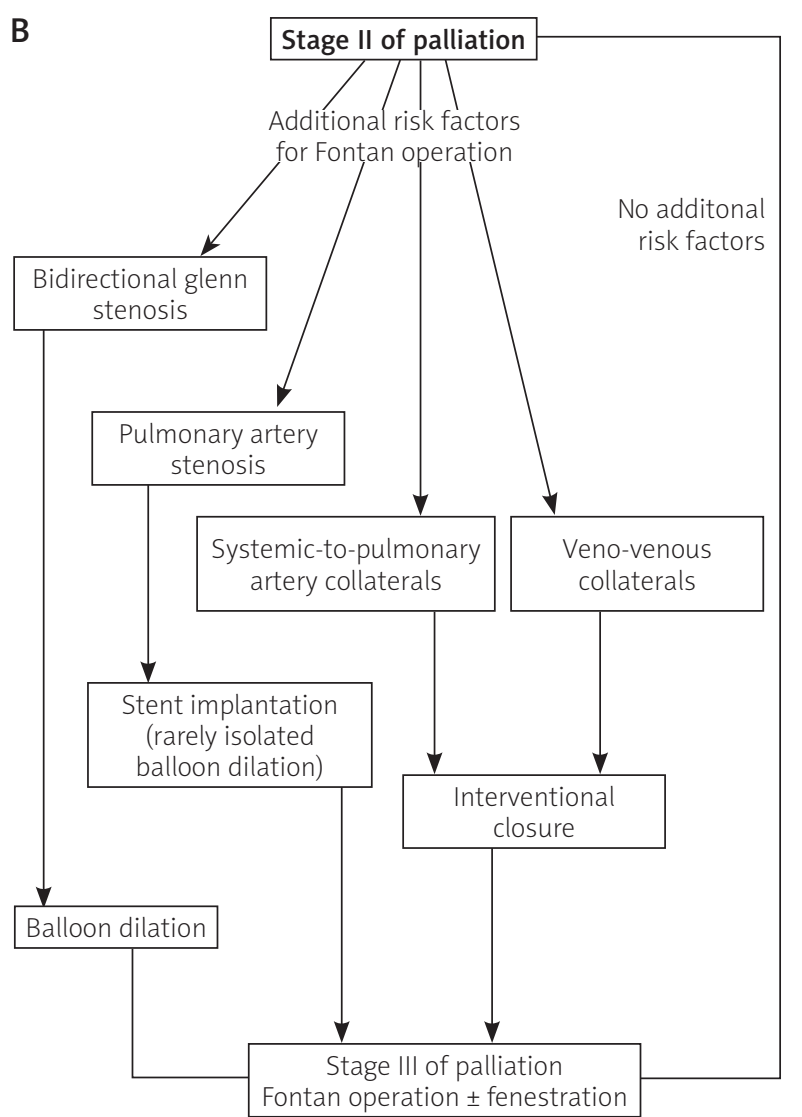

Figure 1. Protocols for supportive interventional treatment in patients with HLHS based on our experience. A - After the first-stage Norwood operation. $\mathbf{B}$ - After the second-stage bidirectional Glenn operation. C - After the third-stage Fontan operation

HLHS - hypoplastic left heart syndrome, Sat. $\mathrm{O}_{2}$-oxygen saturation, ECC - extracorporeal circulation, FO - foramen ovale, RPA - right pulmonary artery, LPA - left pulmonary artery, IAS - interatrial septum

balloon septostomy, with inflation of a balloon catheter placed across the communication, can result in transient improvement [8]. In these cases, restriction usually reoccurs early, especially in patients with a more elastic atrial septum, in whom balloon inflation results only in stretching rather than tearing of the tissue $[9,10]$. The technique of cutting the septum with a Park blade has not gained 
common acceptance due to the high risk of complications; however, this technique has helped with the development of cutting balloons, which allows for the creation of a more predictable tear in the atrial septum [11].

In cases where there is a thick, rigid septum, or if the restriction returns despite surgical septectomy, stent implantation offers more secure relief of the obstruction (Figure 2) $[1,6,12]$. Stents are implanted with a diablo configuration, which reduces the risk of embolisation. This configuration is achieved with post-dilation of both ends of the stent with a larger balloon catheter. The stents are usually easily removed at the next stage of surgical palliation.

\section{Right ventricle-to-pulmonary artery shunt stenosis}

The introduction by Sano et al. of the right ventricle-to-pulmonary artery shunt has led to a lower early mortality rate after first-stage palliation of HLHS. However, re-interventions to an obstructed Sano shunt are more common than for the original subclavian-to-pulmonary artery shunt. Such obstruction is usually a life-threatening complication, which warrants immediate treatment, and most patients present in poor condition, with significant hypoxia and academia. Balloon dilation of the stenosed shunt performed as a rescue intervention often allows for restoration of sufficient pulmonary blood flow and increase in oxygen saturations [1, 2]. It can be done with low - or high-pressure balloon catheters; however, the latter, due to longer deflation times and longer occlusion of the sole source of pulmonary blood flow, increase the risk of bradycardia and cardiac arrest. For proximal

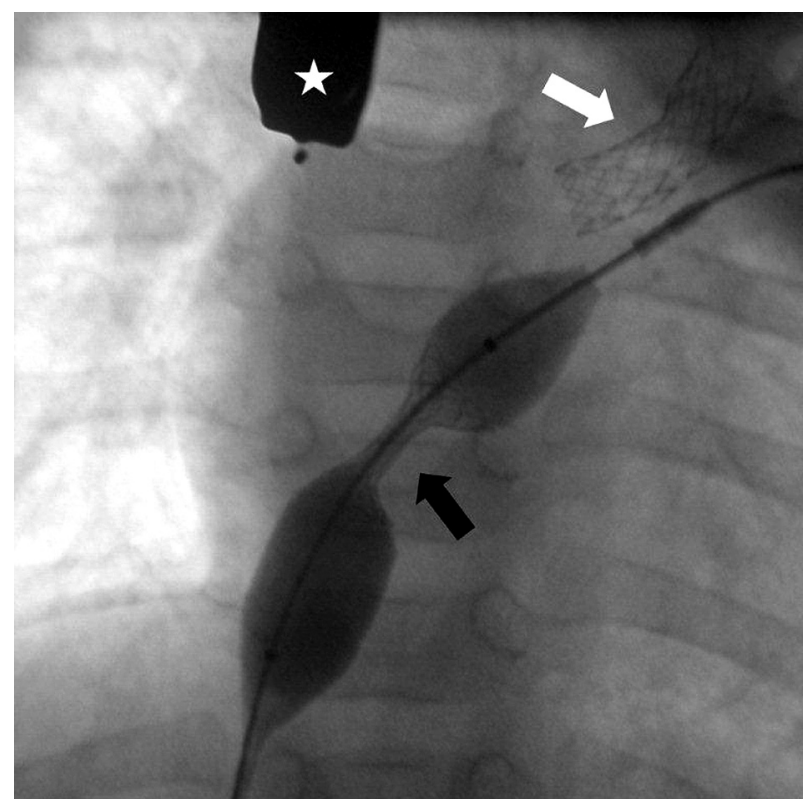

Figure 2. HLHS with restriction of the interatrial communication after second stage palliation. The stent (black arrow) is implanted into the atrial septum under fluoroscopy and transoesophageal echocardiography (star) guidance. A Palmaz Genesis stent (white arrow, Cordis) has previously been implanted to the left pulmonary artery

obstructions at the site of insertion of the shunt to the right ventricle, isolated balloon dilation has limited efficacy, and for these lesions stent implantation should be considered (Figures $3 \mathrm{~A}, \mathrm{~B})[1,2]$.
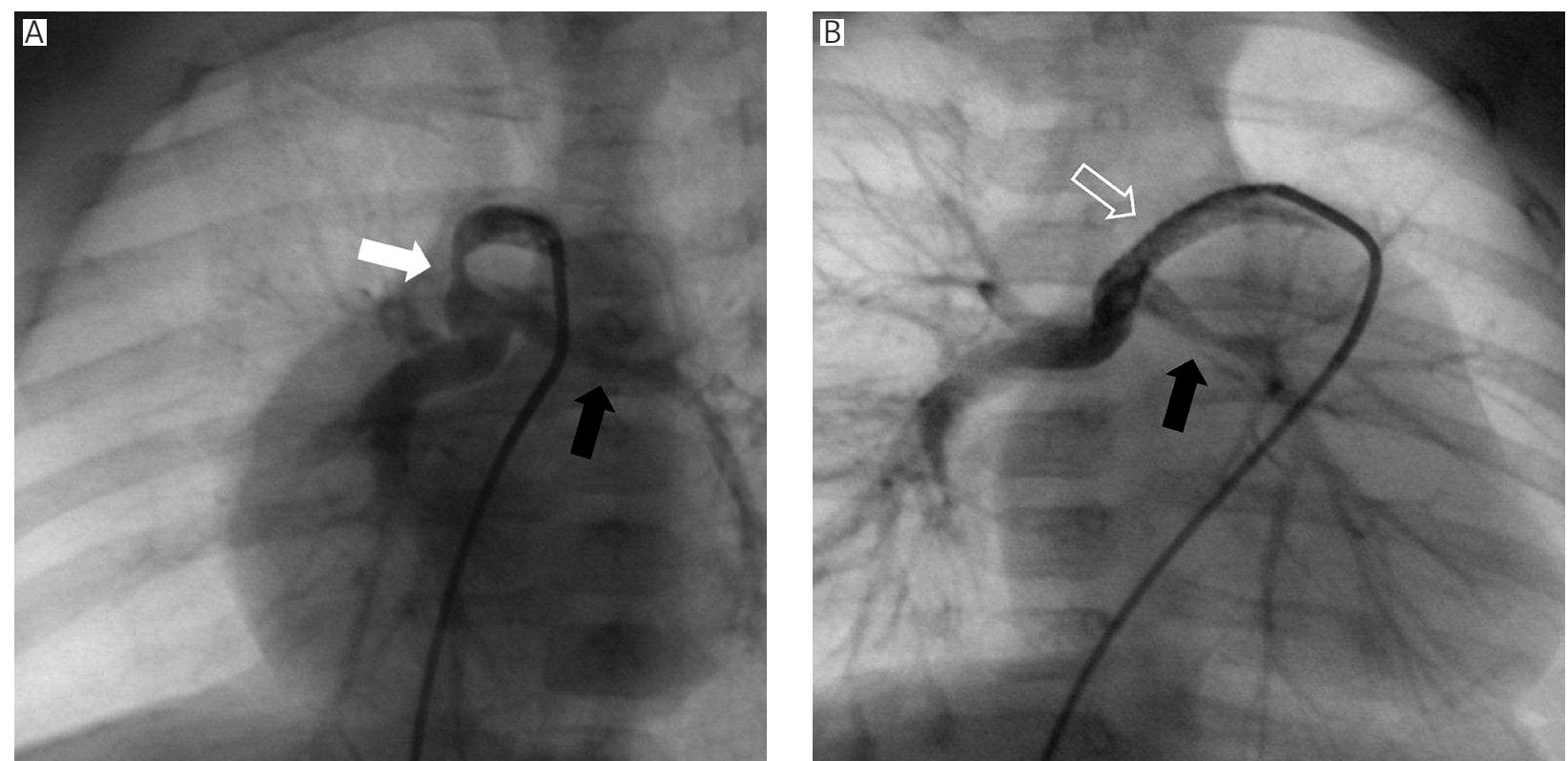

Figure 3. HLHS after first stage of palliation with the Norwood procedure and Sano modification. A - Distal narrowing (white arrow) of the right ventricle-to-pulmonary artery shunt and stenosis of the left pulmonary artery (black arrow). B - After coronary stent implantation to relieve the distal shunt stenosis (empty white arrow) the left pulmonary artery (black arrow) can be more easily seen 


\section{Pulmonary artery stenosis}

The first-stage Norwood operation leads to changes in the geometry of pulmonary arties, and if a Sano shunt is used, up to $50 \%$ of patients may present with proximal pulmonary artery stenosis [13]. However, despite a higher rate of proximal obstructions, in the long term the Sano shunt is better at stimulating the growth of pulmonary arteries.

For most pulmonary artery obstructions, percutaneous balloon dilation is a well-established treatment [14]. This is especially true in the case of distally localised lesions that are difficult to access for surgical reconstruction, in which case less invasive transcatheter interventions offer superior results. Both low - and preferably high-pressure balloon catheters may be utilised with a diameter two or even three times bigger than the diameter of the stenosis. Low-pressure balloons have several advantages including a lower profile, which requires smaller vascular sheaths or faster inflation and deflation times. However, they are ineffective in cases of 'tough' lesions caused by stiff suture lines, postsurgical adhesions, fibrosis, or external compression. In the case of such obstructions, high-pressure balloon catheters with nominal pressures of 10 bar or more should be considered [15, 16].

Isolated balloon dilation is effective in relieving obstructions by more than $50 \%$ in $32-72 \%$ of interventions [16]. For tubular or multilevel obstructions or when the narrowing is a result of kinking or pulling of the vessels after Norwood operation, isolated balloon dilation is ineffective in most patients, and at least one third require further intervention due to restenosis [17]. In such cases stent implantation gives better immediate as well as long-term results (Figures $4 \mathrm{~A}, \mathrm{~B}$ ). This type of intervention is more frequently performed after the second-stage Glenn operation or after Fontan completion. In patients after the first-stage Norwood operation, with the Sano shunt serving as the only source of pulmonary blood flow, stent implantation is rarely performed. Indeed, despite the short-term results, isolated balloon dilation is generally performed initially and stent implantation is reserved for later stages of palliation [1, 2]. Another way of dealing with pulmonary artery stenosis at this early stage is to implant a stent in the operating theatre during the Glenn operation, or transfer the patient to a catheterisation laboratory immediately after the operation $[18,19]$.

Despite the unquestionable benefits of stent implantation for pulmonary artery stenosis, there is still the risk of restenosis, most frequently caused by neointimal proliferation at the edges of the stent or through the struts $[20,21]$. To accommodate the patient's growth, the stent needs to be re-dilated, which exposes the patient to repeat general anaesthesia and requires numerous vessel punctures.

\section{Bidirectional Glenn stenosis}

Stenosis at the site of connection between the superior vena cava and the ipsilateral pulmonary artery leads to elevated venous pressures in the upper body. This, in turn, results in opening of haemodynamically significant veno-venous collaterals, prolonged pleural effusions, and
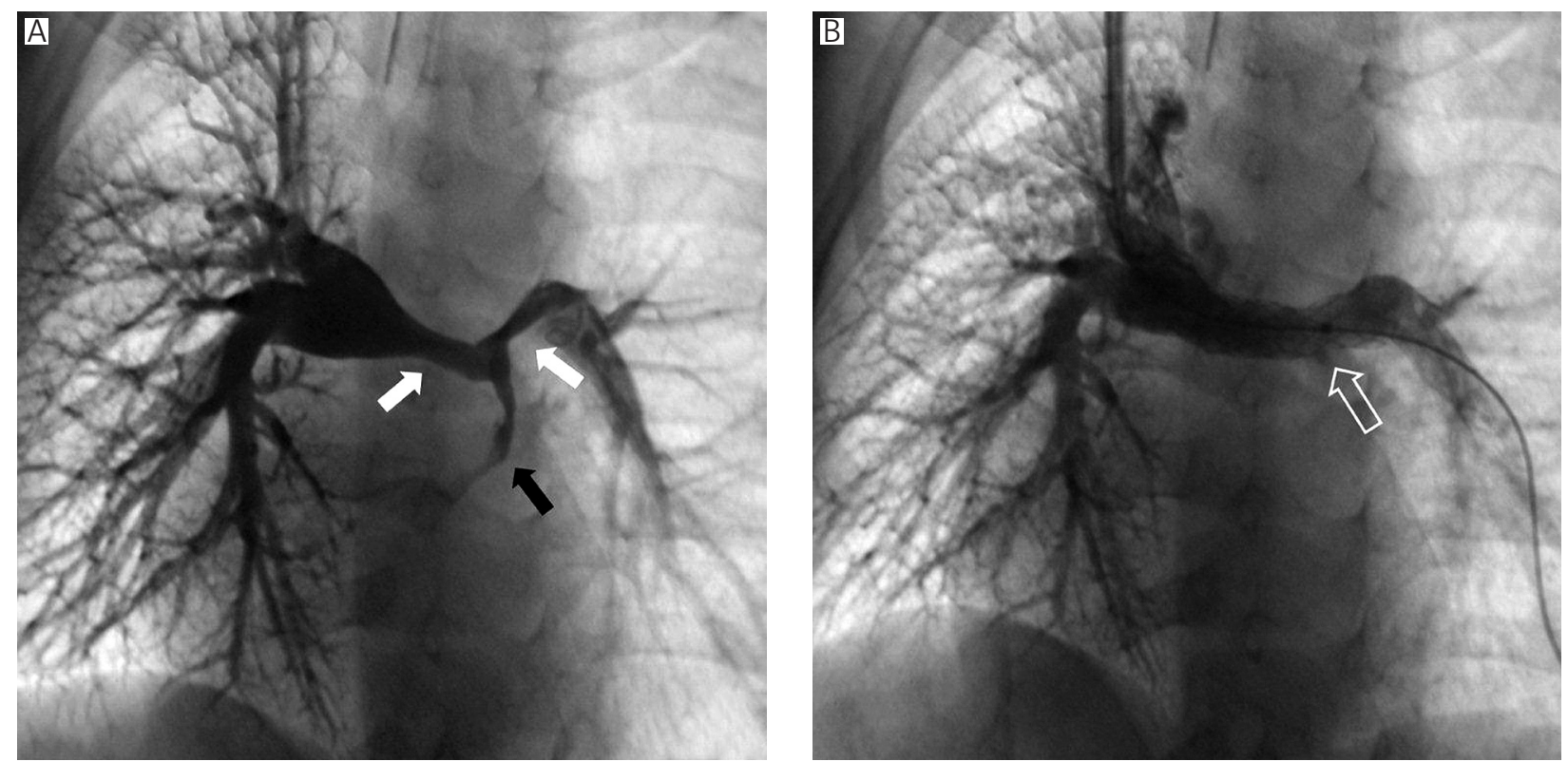

Figure 4. HLHS after second stage palliation. A - Proximal stenosis of the right and left pulmonary arteries (white arrows) with patent right ventricle-to-pulmonary artery shunt (black arrow). B - Implantation of Palmaz Genesis stent (empty white arrow) resulted in expansion of the proximal segments of both pulmonary arteries with reduced flow from the right ventricle-to-pulmonary artery shunt 
in extreme cases superior vena cava syndrome. Isolated balloon dilation is usually effective and may be even performed in the first days after surgery [3]. Low-pressure balloons are preferred, and the diameter of the balloon should not exceed the diameter of the superior vena cava.

\section{Veno-venous collaterals}

Veno-venous collaterals are a common complication in most patients with single ventricle physiology after Glenn of Fontan operations. The onset of such collaterals is directly related to elevated pulmonary artery pressure $[22,23]$. By allowing a right-to-left shunt, the collaterals result in a decrease in arterial oxygen saturations, which is extremely unfavourable in patients who may already have small pulmonary arteries, elevated atrial pressures, significant atrio-ventricular valve regurgitation, or impaired ventricular function. A vicious circle is set in motion, whereby impaired ventricular function leads to an increase in pulmonary artery pressure, which in turn exacerbates the formation of collaterals and a further decrease in oxygen saturations. Prolonged low oxygen saturations may then have a deleterious impact on systolic as well as diastolic function of the single ventricle.

Most of the collaterals may be closed with transcatheter techniques [22, 23]. Small collaterals, with a diameter of around $3 \mathrm{~mm}$, are closed with various types of coils whereas bigger connections require implantation of devices like the Amplatzer Vascular Plug or the Amplatzer Duct Occluder (St. Jude Medical, Figures 5 A, B).

\section{Fenestration closure}

Creation of a communication between the lateral or extracardiac tunnel and the subpulmonary atrium during Fontan operation results in a significant reduction in early complications [24, 25]. In patients with increased risk factors for Fontan completion, the presence of a fenestration limits the intensity and duration of pleural effusions, ascites, and protein-loosing enteropathy. In the long term the right-to-left shunt caused by a fenestration leads to lower oxygen saturations and diminished exercise capacity, and creates a potential risk for paradoxical emboli to coronary or head vessels [26]. For these reasons some authors advocate early fenestration closure form 2 to 3 months after the final stage of surgical palliation $[27,28]$. However, spontaneous fenestration closure is also possible and may occur in $30-40 \%$ of patients after Fontan completion [27]. In the remaining patients balloon test occlusion of the communication should be performed prior to definite closure with a device. The desired response to temporary closure is an increase in oxygen saturation above $90 \%$ with minimal increase in systemic venous pressure [28, 29].

Amplatzer type devices are most commonly used for fenestration closure (Figures $6 \mathrm{~A}, \mathrm{~B}$ ). For small and tunnel-like communications, detachable coils may be implanted. The use of a covered stent for fenestration exclusion has also been reported $[1,30]$. The latter technique allows for complete fenestration closure without leaving any material in the subpulmonary atrium, which may reduce the risk of thromboembolic events. The im-
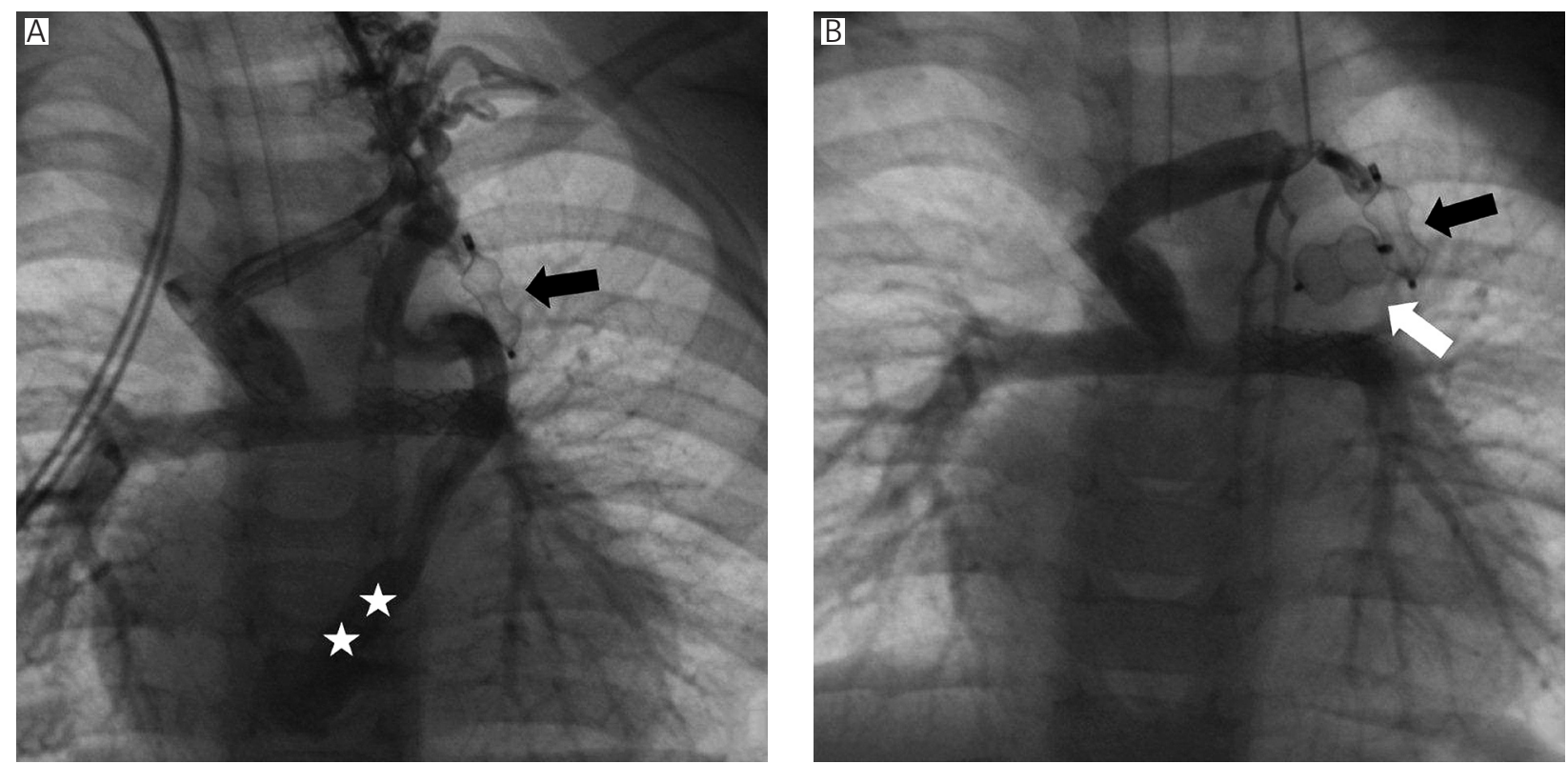

Figure 5. HLHS after second-stage palliation. A - A veno-venous collateral drains to the coronary sinus (stars). In the left pulmonary artery the previously implanted Palmaz Gensis stent can be seen along with the Amplatzer Vascular Plug (black arrow, St. Jude Medical) already deployed in the veno-venous collateral. B - After release of the second device (white arrow) 

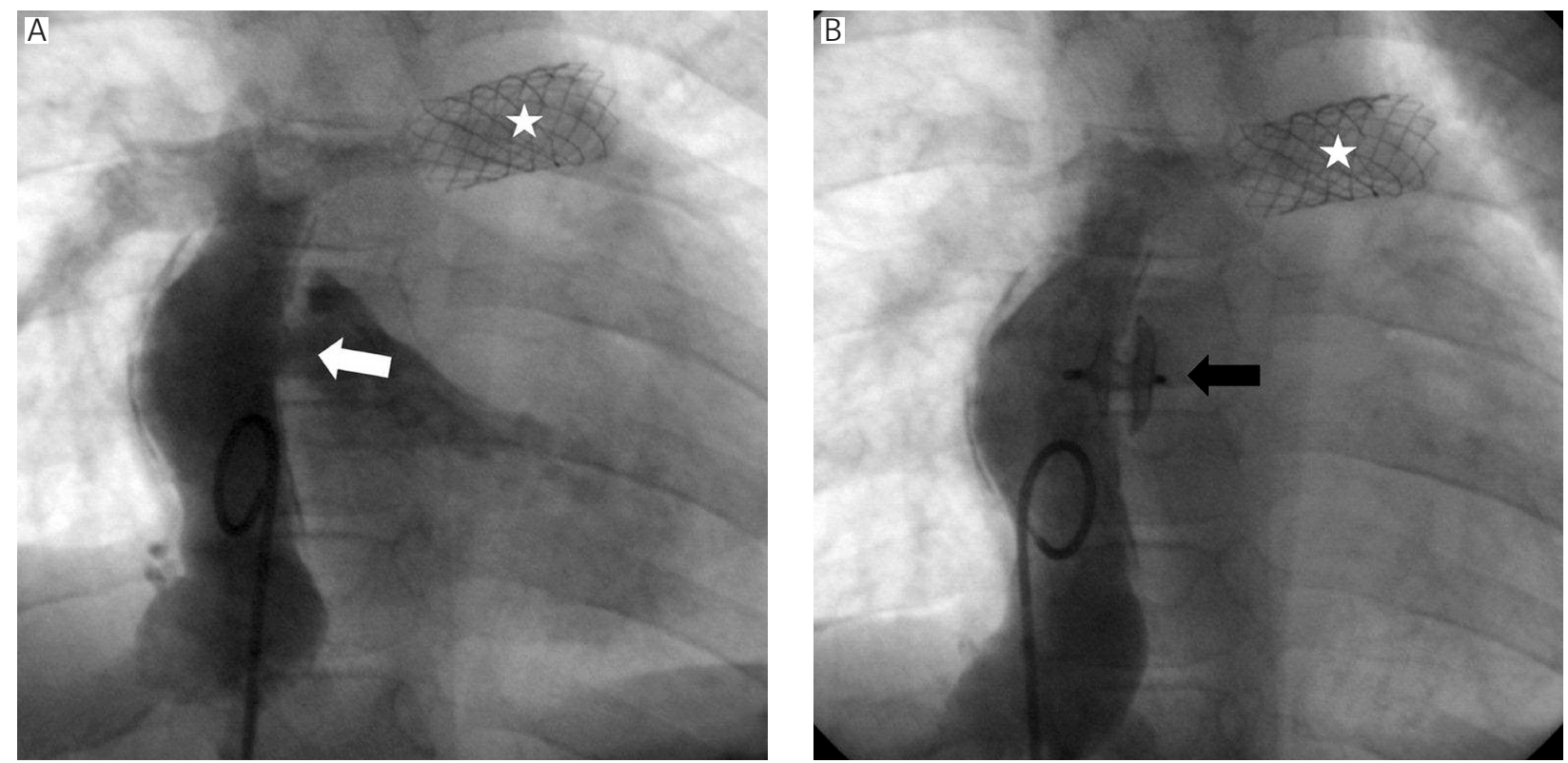

Figure 6. HLHS after third-stage palliation. A - The fenestration (white arrow) between the extracardiac tunnel and the right atrium, with a previously implanted Palmaz Genesis stent (star) in the left pulmonary artery. B After fenestration closure with an Amplatzer Septal Occluder (black arrow, St. Jude Medical), only trivial residual flow can be seen

portant drawback of this treatment is the need to introduce a large vascular sheath (usually 12-13 Fr) to deliver the stent, which may only be possible to perform safely in older patients. The most commonly implanted Amplatzer Septal Occluder or Amplatzer Duct Occluder II requires much smaller delivery sheaths (5-6 Fr). The disadvantage of this type of device is the requirement to leave one of the discs in the subpulmonary atrium to achieve a stable position of the occluder and maximal leak exclusion. In patients with a more superior fenestration, or with pronounced trabeculations of the atrial wall, it may by challenging to properly deploy the left-sided disc. In such cases there is a much higher risk of both compression of the right upper pulmonary vein and provocation of conduction disturbances [28].

\section{Hybrid treatment}

Since Bailey et al. introduced heart transplantation in newborns and neonates with HLHS, maintenance of arterial duct patency until a donor heart was available became a key issue [31]. In the following years several publications described various side effects of prolonged infusion of prostaglandins: fever, respiratory depression, central nervous system bleeding, diarrhoea, cortical hyperostosis, and irreversible changes in the musculature of the pulmonary arteries [32-34]. This stimulated the search for an alternative method to maintain patency of the arterial duct. The first cases of arterial duct stenting in animals were published in the early 90s. Subsequently, Ruiz et al. described this technique in newborns with HLHS awaiting heart transplantation [35]. Later, stenting of the arterial duct with bilateral pulmonary artery banding and balloon atrial septostomy became the standard procedure for patients with HLHS in centres performing heart transplantations.

Akintuerk et al. introduced the following protocol for newborns with HLHS: arterial ductal stenting through the femoral vein or artery with balloon atrial septostomy and bilateral pulmonary artery banding 1-3 days after interventional treatment [36]. In the next stage, 3-6 months later, aortic arch reconstruction is performed with simultaneous bidirectional Glenn operation. The early results are promising, and the procedure allows elimination of one operation with cardiopulmonary bypass.

In 2005 Bacha et al. and later Galantowitz et al. described a modified hybrid approach in patients with HLHS [37-39]. They combined bilateral pulmonary artery banding with arterial duct stenting through a short sheath placed directly in the main pulmonary artery.

Despite the very promising early and mid-term results reported by these centres, most units limit the hybrid approach for patients with high risk for first-stage Norwood operation. This includes newborns in critical condition after asphyxia, post cardiac arrest, with renal or liver failure, or with low birth weight (<2500 g). Successful hybrid treatment of a newborn weighing $1400 \mathrm{~g}$ has been reported [39]. When the hybrid procedure is done as the first step of palliation, the next stage becomes challenging as it combines excision of the previously implanted ductal stent with aortic arch reconstruction, removal of both pulmonary artery bands, and a bidirectional Glenn connection. 
The hybrid approach also brings additional benefits to patients with critical aortic stenosis and borderline hypoplasia of the left ventricle, as when used as the firststage procedure it does not eliminate the possibility of future biventricular repair [40].

\section{Foetal interventions}

In some patients with initially mild anomalies of the left heart structures, further abnormal development during foetal life can progress to typical HLHS. Foetal interventions focus on improving inflow or outflow from the left ventricle. In the case of a restrictive foramen ovale, widening of the interatrial communication may stimulate the growth of the left ventricle by increased blood flow. These interventions are still controversial because mortality rates remain high [41-43]. In selected foetuses balloon dilation of critical aortic stenosis may prevent progressive fibroelastosis of the left ventricle, and therefore increase the likelihood of biventricular repair [44, 45]. However, this scenario is more probable in patients with mild forms of hypoplastic left heart complex rather than with typical HLHS.

Foetal interventions involve risk for both the foetus and the mother. In one of the largest reported studies successful aortic valve dilation was achieved in $66 \%$ of patients, where the foetus was approached through maternal laparotomy [44]. Some authors are convinced that the risk of complications, including premature birth and death of the foetus and the mother, outweigh any potential benefits, and so they advocate planned percutaneous treatment immediately after birth. In this scenario a baby is born in the catheterisation laboratory with a cardiac team ready for immediate postnatal intervention $[42,43]$.

\section{Conclusions}

Recent advances in the field of interventional cardiology, including new devices and techniques, have significantly contributed to improving results of multistage HLHS palliation. Knowledge of the potential interventional options, as well as the limitations, of percutaneous interventions will enable the creation of safe and effective treatment protocols in this highly challenging group of patients.

\section{Acknowledgments}

To Dr David F Lloyd form the Department of Congenital Heart Disease, Evelina London Children's Hospital for his invaluable contribution to the final version of the manuscript.

\section{References}

1. Moszura T, Dryżek P, Góreczny S, et al. A 10-year single-centre experience in percutaneous interventions for multi-stage treatment of hypoplastic left heart syndrome. Cardiology in the Young, available on CJO. doi: 10.1017/S104795111200220X.
2. Moszura T, Dryżek P, Bobkowski W, et al. Percutaneous interventions in patients with hypoplastic left heart syndrome after stage first Norwood operation [Polish]. Postep Kardiol Inter 2011; 7: 277-84.

3. Moszura T, Mazurek-Kula A, Dryzek P, et al. Interventions complementing surgery as part of multistage treatment for hypoplastic left heart syndrome: one center's experience. Pediatr Cardiol 2009; 30: 106-13.

4. Chessa M, Dindar A, Vettukattil JJ, et al. Balloon angioplasty in infants with aortic obstruction after the modified stage I Norwood procedure. Am Heart J 2000; 140: 227-31.

5. Atz AM, Feinstein JA, Jonas RA, et al. Preoperative management of pulmonary venous hypertension in hypoplastic left heart syndrome with restrictive atrial septal defect. Am J Cardiol 1999; 83: $1224-8$

6. Moszura T, Dryżek P, Góreczny S, et al. Stent implantation into the interatrial septum in patients with univentricular heart and a secondary restriction of interatrial communication. Kardiol Pol 2011; 69: 1137-41.

7. Marshall AC, Levine J, Morash D, et al. Results of in utero atrial septoplasty in fetuses with hypoplastic left heart syndrome. Prenatal Diagn 2008; 11: 1023-8.

8. Rao PS. Static balloon dilatation of the atrial septum. Pediatr Cardiol 1996; 17: 349-50.

9. Pedra CA, Neves JR, Pedra SR, et al. New transcatheter techniques for creation or enlargement of atrial septal defects in infants with complex congenital heart disease. Catheter Cardiovasc Interv 2007; 70: 731-9.

10. Galantowicz M, Cheatham JP, Phillips A, et al. Hybrid approach for hypoplastic left heart syndrome: intermediate results after the learning curve. Ann Thorac Surg 2008; 85: 2063-70.

11. Hill SL, Mizelle KM, Vellucci SM, et al. Radiofrequency perforation and cutting balloon septoplasty of intact atrial septum in a newborn with hypoplastic left heart syndrome using transesophageal ICE probe guidance. Catheter Cardiovasc Interv 2005; 64: 214-7.

12. Stumper O, Gewillig M, Vettukattil J, et al. Modified technique of stent fenestration of the atrial septum. Heart 2003; 89: 1227-30.

13. Nakano T, Fukae K, Sonoda H, et al. Follow-up study of pulmonary artery configuration in hypoplastic left heart syndrome. Gen Thorac Cardiovasc Surg 2008; 56: 61-2.

14. Lock JE, Castaneda-Zuniga WR, Fuhrman BP, et al. Balloon dilation angioplasty of hypoplastic and stenotic pulmonary arteries. Circulation 1983; 67: 962-7.

15. Zeevi B, Berant M, Blieden LC. Midterm clinical impact versus procedural success of balloon angioplasty for pulmonary artery stenosis. Pediatr Cardiol 1997; 18: 101-6.

16. Gentles TL, Lock JE, Perry SB. High pressure balloon angioplasty for branch pulmonary artery stenosis: early experience. J Am Coll Cardiol 1993; 22: 867-72.

17. O'Laughlin MP, Perry SB, Lock JE, et al. Use of endovascular stents in congenital heart disease. Circulation 1991; 83: 1923-39.

18. Ing FF. Delivery of stents to target lesions: techniques of intraoperative stent implantation and intraoperative angiograms. Pediatr Cardiol 2005; 26: 260-6.

19. Sreeram N, Emmel M, Ben Mime L, et al. Perioperative placement of stents for relief of proximal pulmonary arterial stenoses in infants. Cardiol Young 2008; 18: 158-64.

20. Shaffer KM, Mullins CE, Grifka RG, et al. Intravascular stents in congenital heart disease: short - and long-term results from a large single-center experience. J Am Coll Cardiol 1998; 31: 661-7. 
21. Ing FF, Grifka RG, Nihill MR, et al. Repeat dilatation of intravascular stents in congenital heart defects. Circulation 1995; 92: 893-7.

22. Andrews RE, Tulloh RM, Anderson DR. Coil occlusion of systemic venous collaterals in hypoplastic left heart syndrome. Heart 2002; 88: 167-9.

23. Heinemann $M$, Breuer J, Steger $V$, et al. Incidence and impact of systemic venous collateral development after Glenn and Fontan procedures. J Thorac Cardiovasc Surg 2001; 49: 172-8.

24. Bridges ND, Castaneda AR. The fenestrated Fontan procedure. Herz 1992; 17: 242-5.

25. Kopf GS, Kleinman CS, Hijazi ZM, et al. Fenestrated Fontan operation with delayed transcatheter closure of atrial septal defect. Improved results in high-risk patients. J Thorac Cardiovasc Surg 1992; 103: 1039-47.

26. Wilson DG, Wisheart JD, Stuart AG. Systemic thromboembolism leading to myocardial infarction and stroke after fenestrated total cavopulmonary connection. Br Heart J 1995; 73: 483-5.

27. Pearl JM, Laks H, Barthell S, et al. Spontaneous closure of fenestrations in an interatrial Gore-Tex patch: application to the Fontan procedure. Ann Thorac Surg 1994; 57: 611-4.

28. Goff DA, Blume ED, Gauvreau K, et al. Clinical outcome of fenestrated Fontan patients after closure: the first 10 years. Circulation 2000; 102: 2094-9.

29. Gamillscheg A, Beitzke A, Stein JI, et al. Transcatheter coil occlusion of residual interatrial communications after Fontan procedure. Heart 1988; 80: 49-53.

30. Marini D, Boudjemline Y, Agnoletti G. Closure of extracardiac Fontan fenestration by using the covered Cheatham Platinum stent. Catheter Cardiovasc Interv 2007; 69: 1002-6.

31. Bailey L, Concepcion W, Shattuck H, et al. Method of heart transplantation for treatment of hypoplastic left heart syndrome. J Thorac Cardiovasc Surg 1986; 92: 1-5.

32. Thanopoulos BD, Andreou A, Frimas C. Prostaglandin E2 administration in infants with ductus-dependent cyanotic congenital heart disease. Eur J Pediatr 1987; 146: 279-82.

33. Woo K, Emery J, Peabody J. Cortical hyperostosis: a complication of prolonged prostaglandin infusion in infants awaiting cardiac transplantation. Pediatrics 1994; 93: 417-20.

34. Caballero S, Torre I, Arias B, et al. Secondary effects of prostaglandin E1 on the management of hypoplastic left heart syndrome while waiting for heart transplantation. An Esp Pediatr 1998; 48: 505-9.

35. Ruiz CE, Gamra H, Zhang HP, et al. Brief report: stenting of the ductus arteriosus as a bridge to cardiac transplantation in infants with the hypoplastic left-heart syndrome. N Engl J Med 1993; 328: 1605-8.

36. Akintuerk H, Michel-Behnke I, Valeske K, et al. Stenting of the arterial duct and banding of the pulmonary arteries: basis for combined Norwood stage I and II repair in hypoplastic left heart. Circulation 2002; 105: 1099-103.

37. Bacha EA, Hijazi ZM. Hybrid procedures in pediatric cardiac surgery. Semin Thorac Cardiovasc Surg Pediatr Card Surg Annu 2005; 8: 78-85.

38. Galantowicz M, Cheatham JP. Lessons learned from the development of a new hybrid strategy for the management of hypoplastic left heart syndrome. Pediatr Cardiol 2005; 26: 190-9.

39. Cua CL, Galantowicz ME, Turner DR, et al. Palliation via hybrid procedure of a 1.4-kg patient with a hypoplastic left heart. Congenit Heart Dis 2007; 2: 191-3.
40. Brown SC, Boshoff D, Eyskens B, et al. Hybrid approach as bridge to biventricular repair in a neonate with critical aortic stenosis and borderline left ventricle. Eur J Cardiothorac Surg 2009; 35: 1080-2.

41. Marshall AC, Levine J, Morash D, et al. Results of in utero atrial septoplasty in fetuses with hypoplastic left heart syndrome. Prenatal Diagn 2008; 11: 1023-8.

42. Pavlovic M, Acharya G, Huhta JC. Controversies of fetal cardiac intervention. Early Hum Dev 2008; 84: 149-53.

43. Simpson JM. Fetal cardiac interventions: worth it? Heart 2009; 95: 1653-5.

44. Wilkins-Haug LE, Tworetzky W, Benson CB, et al. Factors affecting technical success of fetal aortic valve dilation. Ultrasound Obstet Gynecol 2006; 28: 47-52.

45. McElhinney DB, Marshall AC, Wilkins-Haug LE, et al. Predictors of technical success and postnatal biventricular outcome after in utero aortic valvuloplasty for aortic stenosis with evolving hypoplastic left heart syndrome. Circulation 2009; 120: 1482-90. 